\title{
Os acidentes humanos e suas implicações fonoaudiológicas: opiniões de docentes e discentes sobre a formação superior
}

\author{
The human accidents and their implications \\ for functional communication: opinions of teachers \\ and students about higher education
}

Edinalva $\mathrm{N}$ eves $\mathrm{N}$ ascimento ${ }^{1}$

Sandra Regina Gimeniz-Paschoal ${ }^{1}$

${ }^{1}$ Universidade Estadual Paulista. Rua Quirino de Andrade215, República. 01049-010 São Paulo SP. ediquata@gmail.com
Abstract This study aimed to verify the opinion of speech-language pathology teachers and undergraduate students about human accidents and investigate if they are seeking for knowledge and competence in this area. Fifty-two teachers and 95 students from 3 public and 3 private universities in São Paulo took part in this study. Data were collected by means of a questionnaire. According to the participants, accidents are unexpected events that cause physical, functional, emotional and social consequences. Inattentiveness, incaution as well as mental and physical fatiguearefactorsthat contributeto accidents. Thespeech-languagetherapist, the physical therapist, theoccupational therapist and the physicians were considered the most indicated professionals for correcting the sequels caused by external aggressions. They werealso considered the most indicated for carrying out educational actions for the prevention of accidents in form of orientation and lectures for the population of the educational and health units. Teachers and students recognize the importance of the subject, a fact that will help optimizing the educational actions toward accident prevention and introducing new actions and research projects in the universities for improving the competences in this field of knowledge.

Key words Accident prevention, Higher education, Wounds and injuries, Communication
Resumo 0 objetivo desse estudo foi verificar as opiniões de docentes e discentes de cursos de graduação em Fonoaudiologia a respeito dos acidentes humanos e investigar se os mesmos buscam adquirir conhecimentos e competências nesta área do conhecimento. Participaram 52 professores e 95 estudantes detrês faculdades públicas etrês privadas do Estado de São Paulo. Os dados foram coletados com baseem questionários auto-aplicados. Segundo os participantes, acidentes são eventos inesperados que trazem conseqüênciasfísicas, funcionais, emocionais e sociais. A distração, a imprudência, o cansaço mental e físico contribuem para sua ocorrência. 0 fonoaudiólogo, o fisioterapeuta, o terapeuta ocupacional e o médico reabilitam as seqüelas causadas pelos agressores externos eforam os maisindicados para realização de ações educativas de prevenção de acidentes, por meio de orientações e palestras, junto à população das unidades educacionais e de saúde. H ouve reconhecimento da importância da temática pelos docentes ediscentes, sendo favorecedor para otimizar atividades de prevenção de acidentes, bem como introduzir novos projetos de atuação e investigação nas faculdades, o que pareceu importante para ampliar os conhecimentos e competências nesta área do conhecimento.

Palavras-chave Prevenção de acidentes, Educação superior, Ferimentos e lesões, Comunicação 
Introdução

As causas externas acidentais são eventos não intencionais, evitáveise determinadores delesões físicas e emocionai $s^{1}$. Envolvem os acidentes de transporte, os envenenamentos, as quedas, os afogamentos, as sufocações e a exposição a forças mecânicas animadas e inanimadas². Esses agentes agressores físicos, térmicos ou químicos podem causar queimaduras, fraturas e demais ferimentos na região da cabeça e/ou pescoço, resultando em distúrbios diretos e indiretos da comunicação humana.

A morbidade fonoaudiológica é efeito da alteração estrutural e funcional dos tecidos moles e duros que sofrem algum tipo de lesão. Dependendo do local da contusão e do grau de acome timento, o quadro clínico da vítima será amenizado por meio de reabilitação fonoaudiológica e demais especialidades da área da saúde. Entretanto, muitas vezes este quadro será irreversível.

As lesões na região da cabeça e pescoço costumam ser as mais complexas. Tal complexidade se deve à diversi dade e peculiaridades das estruturas anatômicas existentes nestes locais, como sistema nervoso central, ossos, músculos, cartilagens, articulações e complexa vascularização. Uma lesão nesta região pode comprometer a fala, a linguagem, a voz, a audição, a deglutição, a respiração, além de outras funções.

O Brasil é um país que apresenta elevada incidência de traumatismos crânio-encefálicos (TCE). Em 1998, nos hospitais públicos, foram internados 78.981 pacientes com este tipo de lesão, sendo $16.376(20,7 \%)$ crianças menores de dez anos, vítimas principalmentedequedas eacidentes de transporte 3 .

Somente no Estado de São Paulo, em 1997, foram atendidos 29.717 pacientes por lesões e, destes, 3.635 tinham TCE como diagnóstico principal, envolvendo menores de dez anosehomens adultos na faixa etária de 20 a 29 anos. As conseqüências mais comuns foram hemorragias intracranianas que levaram à morte cerca de $10 \%$ dos pacientes 4 .

Um trabalho realizado no hospital das clínicas da UniversidadeEstadual de Campinas (UNICAM P) ressaltou a predominância de TCE entre a população jovem masculina. Dos 206 pacientes atendidos neste hospital com TCE grave, 166 $(80 \%)$ eram do sexo masculino com média de idadede 29 anos. Os acidentes detrânsito predominaram entre eles (74\%), seguidos de quedas e traumas diretos na cabeça por queda de objetos ou agressões físicas ${ }^{5}$.
Em Salvador, no Hospital Geral do Estado da Bahia, foram recebidas 11.028 vítimas de TCE no intervalo de um ano. Desse total, 555 necessitaram de internação hospitalar, 138 tiveram seqüelas neurológicas, incluindo distúrbio cognitivo e afasia, e 127 pacientes faleceram. As principais causas foram acidentes de transporte, agressões físicas e quedas 6 .

Os mais agressivos causadores de lesões no crânio e na face, em todo o mundo, são os acidentesautomobilísticos. Para amenizar o impacto destas causas externas, foram desenvolvidos equipamentos de segurança como cinto e airbag que, instalados no interior dos veículos, protegeriam os passageiros. Porém, eles ainda não são acessíveis ou utilizados pela maioria da população e nem se mostraram totalmente seguros.

Durante 0 acidente, por exemplo, a inflação do airbag pressiona o tórax, membros superiores e a região da cabeça e do pescoço causando graves esfoliações, lacerações e fraturas nos ossos da face e dentes ${ }^{7,8}$. A elevada temperatura duranteseu enchimento, assim como a liberação de gases derivados do sódio, nos casos de perfuração do equipamento, trazem queimaduras térmicas e químicas na pele, principalmente a facial ${ }^{9}$. Além disso, durante o acionamento, é emitidauma pressão sonora deaproximadamente 168 $\mathrm{dB}$, a qual pode perfurar a membrana timpânica e causar perda auditiva, principalmente entre as freqüências de 2000 e 4000 HZ, além de fístula perilinfática, zumbido evertigem ${ }^{10}$.

0 envolvimento de adultos jovens, entre $16 \mathrm{e}$ 30 anos, associado à inexperiência, imprudência eirresponsabilidade, explica a el evada incidência de acidente automobilístico nesta faixa etária. Dentre todos os traumatismos ocorridos, a cabeça está envolvida em mais de $70 \%$ dos casos, 0 que pode causar dano cerebral ${ }^{11}$.

A lesão cerebral éresponsável por uma diversidade de alterações motoras, cognitivas e comportamentais. Quando atinge o hemisfério cerebral esquerdo, podem ocorrer as afasias, com comprometimento nos componentes fonológicos, sintáticos, lexicais ediscursivos, além de perturbações na recepção e/ou expressão da linguagem oral e escrita. Se acometer o hemisfério direito, pode haver alteração na função espacial, prosódia e expressão emotiva, além de afetar as capacidades de concentração, memorização, orientação espacial, resolução de problemas e linguagem $^{12,13}$.

Dependendo do tipo e da gravidade do traumatismo, ainda podem ocorrer alterações nas estruturas do sistema auditivo, desde o conduto 
externo até as vias auditivas centrais. Pode haver perfuração da membrana timpânica, desarticulação da cadeia ossicular eacúmulo de sangueno ouvido médio, resultando em perdas auditivas condutivas. Além disso, pode ocorrer hemorragia no ouvido interno e degeneração dos neurônios cocleares, causando perdas auditivas neurossenssoriais ${ }^{14}$.

Os agentes agressores podem fraturar o osso temporal, em sua porção petrosa, resultando em perda auditiva neurossensorial profunda, anacusia e presença de zumbido e tontura ${ }^{15,16}$. 0 comprometimento desta estrutura pode acometer, ainda, o trajeto do nervo facial, causando paralisia na face em até $25 \%$ dos $\operatorname{cas}^{17,18}$.

A paralisia facial traz alterações na mastigação, sucção, gustação e respiração, bem como inibe os movimentos da mímica e expressão facial. A fala também fica comprometida, principalmentena produção das consoantes bilabiais / $\mathrm{p} /, / \mathrm{b} /, / \mathrm{m} /$ e nas labiodentais /f/ e/v/. Ainda assim, a deformidade altera a estética da face, levando a pessoa ao constrangimento, isolamento social e até mesmo à depressão $0^{19,20}$.

Os músculos e articulações da região da cabeça e pescoço também costumam ser atingidos pelos agentes agressores e, quando danificados, alteram a estrutura do sistema estomatognático e comprometem as funções de mastigação, sucção, respiração e fonoarticulação. Nos casos em que as fraturas são complexas, pode ocorrer alteração na sensibilidade e motricidade dos órgãos fonoarticulatórios, modificando as fases antecipatória, preparatória e oral da deglutição, trazendo, assim, riscos de pneumonia aspirativa ${ }^{21}$.

0 trauma brusco no pescoço pode dilacerar as mucosas da laringe, lesionar as pregas vocaise comprometer a via aérea superior, acarretando dificuldade respiratória, alteração vocal e dores durante a deglutição ${ }^{22,23}$.

A mortalidade por causas externas ocupa a segunda ou terceira posição mundial e, infelizmente, tem perspectivas deaumento para os próximosanos $s^{24,25}$. 0 índice de injúriasfísicas eóbitos por acidentes é assustador, assim como os custos diretos e indiretos absorvidos por esta causa $^{26}$. O s agentes agressores comumente estão presentes nos lares, escolas, locais de lazer e de trabalho, tornando estes ambientes facilitadores para a ocorrência de um acidente. Na maioria das vezes, as pessoas desconhecem os riscos sob os quais estão expostas, sendo carentes de informações educativas quelhes orientem sobrecomo prevenir as injúrias.

A prevenção éa melhor solução para as con- seqüências dos acidentes humanos e deveria ser sensibilizada na formação superior de todos os profissionais da saúde, inclusive do fonoaudiólogo, que poderia estruturar e desenvolver programas educativos junto à comunidade, para que as pessoas pudessem compreender a gravidade deste problema e desenvolver estilos de vida e ambientes mais seguros.

Existe, portanto, a necessidade de se contemplar na formação do fonoaudiólogo aspectos teóricos e práticos sobre este tema para que ele possa real izar ações educativas para preven ção econtrole dos acidentes. Entretanto, não foi encontrado na literatura nenhum estudo que investigue como ocorre a formação deste profissional em relação aos acidentes humanos, nem mesmo um quefocalizecomo docentes ediscentes se posicionam a respeito, conhecimentos estes que seriam essenciais para refletir etentar implementar uma formação desta natureza, no sentido de contribuir com a diminuição deste sério problema de saúde pública ecom uma formação superior mais adequada à realidade da população.

0 objetivo deste estudo foi verificar as opiniões de docentes e discentes de cursos de graduação em Fonoaudiologia a respeito dos acidentes humanos e investigar se os mesmos buscam adquirir conhecimentos e competências nesta área do conhecimento.

\section{M étodo}

O projeto de pesquisa foi encaminhado para apreciação do Comitêde Ética da Universidade Estadual Paulista "Júlio de M esquita Filho", sendo por ele aprovado - protocolo 396/2005. Ressalta-se que todos os princípios éticos foram cumpridos conforme versa a Resolução nº 196/96.

\section{Ambiente}

Foram convidadas a participar deste estudo todas as instituições formadoras de fonoaudiólogos do Estado deSão Paulo. Concordaram participar seis, sendo três públicas e três privadas.

\section{Participantes}

Todos os 79 professores dos cursos e os 124 alunos que cursavam o quarto ano foram convidados a responder um instrumento de pesquisa. Aceitaram participar 52 docentes ( 37 das públicas e 15 das privadas) e 95 discentes ( 68 das públicas e 27 das privadas). 
Dentreos docentes, 45 (86,5\%) são do gênero feminino e $7(13,4 \%)$ do gênero masculino. Apresentavam idade entre 26 e 65 anos com média de 41,4 anos e desvio padrão de 7,6. 0 tempo decorrido após a graduação variou de 5 a 33 anos, com média de 20 anos e desvio padrão de 6,9. Em relação á área de formação, 39 são fonoaudiólogos, três psicólogos, três médicos, dois biólogos, um lingüista, um dentista, dois fonoaudiólogos/lingüistas e um fonoaudiólogo/psicólogo.

D os discentes participantes, 91 (96\%) são do gênero feminino e 4 (4\%), do masculino. A idade variou entre 20 e 29 anos com média de 22,6 anos e desvio padrão de 1,7.

\section{Coleta de dados}

A coleta de dados ocorreu entre 14/03/2005 e 05/09/2005.

Pelo fato de serem escassos, na literatura, os estudos que mostram a opinião dos professores e alunos dos cursos de Fonoaudiologia sobre os acidentes humanos (causas, conseqüências e formas de atuação preventiva), optou-se por realizar uma coleta preliminar, por meio deentrevista, para posterior estruturação de um questionário definitivo de pesquisa. Participaram desta etapa onze estudantes, sendo cinco da faculdade privada e seis da pública. 0 tamanho da amostra foi definido no decorrer do trabalho, ao perceber-se a estabilidade e similaridade das respostas dos informantes durante realização das entrevistas.

Todas as entrevistas foram gravadas e, posteriormente, transcritas na íntegra. Asinformações transcritas foram analisadas e separadas em tre chos que se assemelhavam quanto ao tema ou idéiacentral.

Com os dados obtidos nas entrevistas, foi elaborado um questionário para alunos e, a partir deste, projetado outro para professores. Os dois modelos foram praticamente semelhantes quanto à forma e conteúdo.

A primeira parte do questionário foi composta por questões abertas e fechadas, com uso principal de questões dicotômicas e de múltipla escoIha. $\mathrm{Na}$ segunda parte do questionário, foram organizados os dados de identificação do respondente e da instituição ao qual está vinculado.

Foram formuladas vinte e oito questões para alunos e trinta para professores. As questões foram encaminhadas para apreciação de três juízes, com experiência em pesquisa, que apresentaram sugestões sobre 0 instrumento de coleta de da- dos. Esses instrumentos foram submetidosà pré teste com uma população semel hante àquela da amostra final.

Para todos os professores participantes da amostra final foram encaminhados, por e-mail, a carta de apresentação do trabalho, o questionário elaborado para docentes e o termo de consentimento informado.

Para os al unos de quatro faculdades, os questionários foram aplicados pessoalmente e em grupo, aos finais das aulas e dos atendimentos terapêuticos. Em outras duas instituições, foi solicitada a colaboração de dois professores do curso (sendo um auxiliado pela representante discente de sala do quarto ano), que aceitaram aplicar o instrumento de pesquisa, encaminhado via sedex. Foi enviado também um envelope selado para volta, preenchido com o nome e endereço da pesquisadora, além da carta de apresentação do trabalho e o termo de consentimento informado.

\section{Análise dos dados}

A análise das questões abertas dos questionários ocorreu por meio da leitura das respostas dos professores e alunos, além da classificação em categorias das palavras, conjuntos de palavras e expressões que se aproximavam semanticamente. Esse material foi encaminhado para trêsjuízes fonoaudiólogos a fim de julgarem a proposta de categorização que se realizou. Com a devolução dos materiais, calculou-se o índice de concordância dosjuízes com a classificação realizada previamente pela pesquisadora. Obteve-se resultados correspondentes a $92,3 \%, 95,9 \%$ e $97,2 \%$.

As respostas das questões fechadas dos docentes e discentes foram somadas separadamente para cada classe de participante e subdividas de acordo com cada faculdade. Calculando-sea porcentagem de aparição das respostas, percebeu-se quenão houvediferença estatística entreas faculdades públicas e privadas. Desta forma, optou-se por fazer uma análise comparativa tomando como foco os dados dos docentes e discentes.

Assim, as informações das questões fechadas foram analisadas estatisticamente, com utilização das freqüências absolutas e porcentagens, calculadas em relação ao número total de participantes dos dois segmentos. U tilizou-se o teste qui-quadrado, com auxílio do software InStat, versão 1997, para medir o grau de significância da associação entre variáveis. 


\section{Resultados}

Analisando a concepção dos docentes ediscentes dos cursos de Fonoaudiologia sobre "acidentes", verificou-se que, para os dois segmentos, esses são eventos inesperados ( $n=134$ ou $91,2 \%$ ) que trazem conseqüências físicas, funcionais, emocionais e sociais.

Para os docentes, os fatores que mais facilitam a sua ocorrência são 0 cansaço mental $(n=$ 49 ou $94,2 \%)$, o estresse ( $n=48$ ou $92,3 \%)$, a ingestão de bebidas alcoólicas ( 47 ou $90,3 \%$ ) e a ingestão de drogas (46 ou 88,4\%). Na opinião dos discentes, a distração éa mais predisponente ( $n=93$ ou $97,8 \%$ ), seguida da imprudência ( $n=$ 91 ou $95,7 \%$ ) e do cansaço mental ( $n=85$ ou $89,4 \%$ ). Houve diferença extremamente significante em "ingestão de bebidas alcoólicas" ( $\times 2=$ $122,10$ e $p<0,001)$ e "ingestão de drogas" ( $x 2=$ $118,23$ e $p<0,001)$, mencionados somente pelos docentes.

Em relação às informações sobre acidentes, $39(75 \%)$ docentes e $85(89,5 \%)$ discentes afirmaram tê las recebido, havendo diferença significante entre as respostas dos participantes ( $x 2$ $=4,294$ ep $<0,0383$ ). Os principais informes obtidos pelos docentes foram sobre prevenção de acidentes ( $n=36$ ou $69,2 \%$ ) e primeiros socorros ( $n=27$ ou $51,9 \%$ ) e pel os graduandos foram acerca de primeiros socorros ( $n=74$ ou $77,8 \%$ ) eatividades preventivas das injúrias ( $n=60$ ou $63,1 \%$ ). Estatisticamente, foi encontrada diferença significante em "primeiros socorros" ( $x 2=$ $9,370$ e $p<0,0022)$. Outras informações recebidas pelos dois segmentos foram sobre "epidemiologia" ( $n=51$ ou $34,7 \%)$, "reabilitação" ( $n=50$ ou $34 \%$ ), "fatores derisco" ( $n=1$ ou $0,7 \%$ ) e"políticas públicas" ( $n=1$ ou $0,7 \%$ ).

Os principais meios condutores das informações para os docentes foram palestras ( $n=22$ ou $42,3 \%$ ), panfletos ( $n=21$ ou $40,3 \%$ ), tel evisão ( $n=20$ ou $38,4 \%$ ) e experiência profissional $(n=$ 20 ou $38,4 \%$ ). Para os discentes, os cursos ( $n=58$ ou $61,0 \%$ ), televisão ( $n=48$ ou $50,5 \%$ ), palestras ( $n=46$ ou $48,4 \%$ ) e panfletos ( $n=39$ ou $41,0 \%$ ) foram os mais comuns. As informações foram recebidas pelos professores principalmente nos locais de trabalho ( $n=25$ ou $48 \%$ ) e hospitais ( $n=21$ ou $40,3 \%$ ). Com os discentes, foram obtidosna auto-escola ( $n=62$ ou $65,2 \%$ ) eem escolas de ensino regular ( $n=57$ ou $60 \%$ ).

Tanto professores quanto graduandos dos cursos de Fonoaudiologia responderam que 0 fonoaudiólogo ( $n=146$ ou $99,3 \%$ ), o fisioterapeuta $(n=145$ ou $98,6 \%$ ), o terapeuta ocupacio- nal ( $n=142$ ou $96,6 \%)$, o médico ( $n=141$ ou $95,9 \%$ ) eo psicólogo ( $n=140$ ou $95,2 \%$ ) eram os profissionais mais indicados para reabilitar as patologias das pessoas acidentadas. Praticamente todos os discentes ( $n=95$ ou $100 \%$ ) e quase todos os docentes ( $n=51$ ou $98 \%$ ) reconheceram que os acidentes trazem conseqüências que envolvem a atuação do fonoaudiólogo.

A maioria dos docentes ( $n=48$ ou $92,3 \%$ ) e discentes ( $n=82$ ou $86,3 \%$ ) afirmou que os acidentes podem ser prevenidos em sua maior parte, sinalizando os profissionais da saúde, principalmenteo médico ( $n=121$ ou $82,3 \%$ ), o fisioterapeuta ( $n=117$ ou $79,6 \%$ ), o enfermeiro ( $n=$ 116 ou $78,9 \%$ ) e o fonoaudiólogo $(n=113$ ou $76,9 \%$ ) para realização das ações preventivas. $\mathrm{Na}$ Tabela 1, podem ser observadas as sugestões de atividades preventivas que poderiam ser realizadas para se evitar a ocorrência de acidentes.

A orientação foi o tipo de atividade maisindicada pelos docentes ( $n=35$ ou $25,8 \%$ ), podendo ser individual ou coletiva, presencial ou à distância, bem como no trabalho ou em ambientes educacionais e de saúde. Para os discentes, as palestras informativas para a população são as principais ações preventivas que poderiam ser realizadas ( $n=50$ ou $28,6 \%$ ), seguidas das orientações ( $n=40$ ou $22,8 \%$ ) quanto aos cuidados que devem ser tomados diante das situações de risco e sobre as causas e consequêencias dos acidentes.

A Tabela 2 indica os locais onde as atividades preventivas poderiam ser realizadas.

Os lugares mais freqüentemente apontados para a realização das atividades, na opinião dos docentes, foram as Unidades Básicas de Saúde (UBS) ( $n=50$ ou $96,1 \%$ ), escolas ( $n=49$ ou $94,2 \%$ ), locais de trabalho ( $n=48$ ou $92,3 \%$ ), hospitais ( $n=47$ ou 90,3\%), Unidades de Saúde da Família (USFs) ( $n=44$ ou 84,6\%), berçários ( $n=41$ ou $78,8 \%$ ) e clínicas particulares $(n=41$ ou $78,8 \%)$. Segundo a opinião dos discentes, as escolas ( $n=93$ ou $97,8 \%$ ) foram os locais mais indicados para tais atividades, seguidas das USFs ( $n=83$ ou $87,3 \%$ ), UBSs $(n=81$ ou $85,2 \%$, locais de trabalho ( $n=81$ ou $85,2 \%$ ), hospitais ( $n=76$ ou $80 \%$ ) eclínicas particulares ( $n=69$ ou $72,6 \%$ ).

Quando questionados sobre a realização de alguma atividade relacionada ao tema, seja atendimento terapêutico, orientação aos familiares de pacientes acidentados, atividades preventivas, entre outras, $28(53,8 \%)$ professores e 34 (35,8\%) estudantes afirmaram têla realizado, havendo diferença significativa entreas respostas ( $x 2=3,783$, $p<0,0518)$. Os docentes realizaram orientações ( $n=23$ ou $44,2 \%$ ) eações preventivas deacidentes 
( $n=19$ ou $36,5 \%)$, além de reabilitação $(n=16$ ou $30,7 \%$ ) das patologias causadas por eles, enquanto os discentes estiveram envolvidos principalmente com orientações ( $n=30$ ou $31,5 \%$ ) e ações pre ventivas ( $n=24$ ou $25,2 \%$ ). As ações dos dois segmentos foram direcionadas, principalmente, para os adultos ( $n=40$ ou $27,2 \%$ ), crianças ( $n=37$ ou $25,2 \%$ ) e pacientes ( $n=31$ ou $21 \%$ ).

Tabela 1. Atividades preventivas que poderiam ser realizadas para se evitar os acidentes ( $\mathrm{N}=135$ respostas dos docentes e $\mathrm{N}=175$ respostas dos discentes).

\begin{tabular}{|c|c|c|c|c|c|c|}
\hline \multirow{2}{*}{ Tipo de atividade preventiva } & \multicolumn{2}{|c|}{ Docentes } & \multicolumn{2}{|c|}{ Discentes } & \multicolumn{2}{|c|}{ Total } \\
\hline & $f$ & $\%$ & $f$ & $\%$ & $f$ & $\%$ \\
\hline Orientação & 35 & 25,8 & 40 & 22,8 & 75 & 24,1 \\
\hline Palestra* & 20 & 14,8 & 50 & 28,6 & 70 & 22,5 \\
\hline Distribuição de material educativo & 14 & 10,7 & 27 & 15,4 & 41 & 13,2 \\
\hline Curso & 11 & 8,1 & 21 & 12,0 & 32 & 10,3 \\
\hline Abordagem no tema na formação profissional & 13 & 9,6 & 7 & 4,0 & 20 & 6,5 \\
\hline Divulgação do tema na mídia & 10 & 7,4 & 4 & 2,3 & 14 & 4,5 \\
\hline Campanha & 5 & 3,7 & 7 & 4,0 & 12 & 3,9 \\
\hline Atividade educativa comunitária & 8 & 5,9 & 3 & 1,7 & 11 & 3,5 \\
\hline A bordagem do tema em aula & 5 & 3,7 & 5 & 2,9 & 10 & 3,2 \\
\hline Exposição de material educativo & 6 & 4,4 & 4 & 2,3 & 10 & 3,2 \\
\hline Divulgação em evento científico & 3 & 2,2 & 2 & 1,1 & 5 & 1,6 \\
\hline Abordagem do tema na formação básica & 3 & 2,2 & - & - & 3 & 1,0 \\
\hline Ação governamental & 2 & 1,5 & 1 & 0,6 & 3 & 1,0 \\
\hline Atitudes seguras & - & - & 3 & 1,7 & 3 & 1,0 \\
\hline Pesquisa & - & - & 1 & 0,6 & 1 & 0,3 \\
\hline
\end{tabular}

$*\left(p<0,0062 ; x^{2}=7,482 ; g . l=1\right)$.

Tabela 2. Local de realização das atividades preventivas de acidentes ( $N=52$ docentes e $\mathrm{N}=95$ discentes).

\begin{tabular}{|c|c|c|c|c|c|c|}
\hline \multirow{2}{*}{ Local para atividades preventivas } & \multicolumn{2}{|c|}{ Docentes } & \multicolumn{2}{|c|}{ Discentes } & \multicolumn{2}{|c|}{ Total } \\
\hline & $f$ & $\%$ & $f$ & $\%$ & $f$ & $\%$ \\
\hline Escola & 49 & 94,2 & 93 & 97,8 & 142 & 96,6 \\
\hline Unidade Básica de Saúde (UBS) & 50 & 96,1 & 81 & 85,2 & 131 & 89,1 \\
\hline Trabalho & 48 & 92,3 & 81 & 85,2 & 129 & 87,8 \\
\hline Unidade de Saúde da Família (USF) & 44 & 84,6 & 83 & 87,3 & 127 & 86,4 \\
\hline Hospital & 47 & 90,3 & 76 & 80,0 & 123 & 83,7 \\
\hline Clinica & 41 & 78,8 & 69 & 72,6 & 110 & 74,8 \\
\hline Residência & 40 & 76,9 & 65 & 68,4 & 105 & 71,4 \\
\hline Berçário & 41 & 78,8 & 63 & 66,3 & 104 & 70,7 \\
\hline Todos os locais* & 6 & 11,5 & - & - & 6 & 4,0 \\
\hline Imprensa & 2 & 3,8 & 1 & 1,0 & 3 & 2,0 \\
\hline Ruas & 1 & 1,9 & 2 & 2,1 & 3 & 2,0 \\
\hline Estradas & 2 & 3,8 & - & - & 2 & 1,4 \\
\hline Bulas & 1 & 1,9 & - & - & 1 & 0,7 \\
\hline Empresas de turismo & 1 & 1,9 & - & - & 1 & 0,7 \\
\hline Grupo da terceira idade & 1 & 1,9 & - & - & 1 & 0,7 \\
\hline Locais de lazer & 1 & 1,9 & - & - & 1 & 0,7 \\
\hline Locais de prática de esporte & 1 & 1,9 & - & - & 1 & 0,7 \\
\hline Universidades & - & - & 1 & 1,0 & 1 & 0,7 \\
\hline
\end{tabular}

$*\left(p<0,032 ; x^{2}=8,671 ; g . l=1\right)$. 
Perguntou-se ainda aos docentes e discentes se eles acreditavam existir alguma relação entre os acidentes e a Fonoaudiologia. Dentre os participantes, $49(94,2 \%)$ docentes e $89(93,7 \%)$ discentes responderam positivamente. Ao serem questionados sobre o tipo de relação existente entre o tema e o curso em estudo, foram recebidas 61 respostas dos docentes e 96 dos discentes. Das respostas obtidas dos professores, 41 $(67,4 \%)$ se direcionaram para a possibilidade de atuação curativa frente aos danos comunicativos causados pel os acidentes. Outras $13(21,3 \%)$ apontaram o fonoaudiólogo como profissional capaz de planejar e desenvolver atividades que impeçam a ocorrência de injúrias. Sete respostas $(11,5 \%)$ levantaram a presença de riscos para a ocorrência deacidente detrabal ho durantea atuação desteprofissional. Dentreos 96 relatos apresentados pelos discentes, $67(69,8 \%)$ voltaramse para a ação curativa e $29(30,2 \%)$, para a prevenção dos acidentes.

Quanto ao processo de ensino-aprendizagem, foi questionado aos docentes se el es ministravam al guma disciplina ou atividade que abordasse, de al guma forma, o conteúdo dos acidentes. Aos discentes, questionou-se a percepção do tema em alguma disciplina ou atividade proposta pelos docentes do curso. Os resultados indicaram que $50 \%$ dos professores ministram al guma disciplina ou atividade relacionada ao tema, sendo confirmada por $42,1 \%$ dos graduandos. A maioria dos docentes $(74,4 \%)$ ediscentes $(88,5 \%)$ afirmou queo conteúdo foi contemplado em disciplinas curriculares, principalmente naquelas de Audiologia, Fonoaudiologia Preventiva, Fonoaudiologia H ospitalar, Distúrbio de linguagem no adulto e Biossegurança, bem como nos estágios de Fonoaudiologia institucional. Os conteúdos foram mencionados, principalmente, durantea exposição de aulas teóricas, supervisões e estágios curriculares.

Os professores também foram questionados sobre a possibilidade de atuação com os acidentes. Cerca de $80 \%$ destes profissionais responde ram de forma afirmativa, sinalizando a contribuição que poderiam oferecer na formação do fonoaudiólogo em relação ao tema, seja na capacitação para atuação curativa, preventiva ou complementação das disciplinas do curso.

A maioria dos docentes ( $n=40$ ou $76,9 \%$ ) e discentes ( $n=84$ ou $88,4 \%$ ) afirmou ser possível inserir ou complementar o conteúdo dos acidentes no currículo dos cursos de Fonoaudiologia, principalmente nas disciplinas de Fonoaudiologia Preventiva e Saúde Pública, por meio da aula expositiva teórica ( $n=10$ ou $69,4 \%$ ).

\section{Discussão}

$\mathrm{N}$ a visão dos docentes e discentes, os acidentes acontecem com as pessoas de forma inesperada/ imprevisível. No entanto, as respostas parecem ser contraditórias quando eles mencionam que esses eventos podem ser prevenidos. Como prevenir sem prever a sua ocorrência? O M inistério da Saúde fala sobre a previsibilidade dos acidentes, mas reconhece que as pessoas precisam estar conscientes das situações de risco, serem capazes de identificar os perigos que as cercam e realizar mudanças que garantam sua segurança. 0 fonoaudiólogo e os demais profissionais que mantêm proximidade com a população poderiam ajudar neste sentido, se tivessem conhecimentos bem definidos sobre 0 assunto e estivessem sensibilizados para a prevenção.

Alguns conhecimentos sobre prevenção de acidentes foram recebidos nos cursos realizados nas auto-escolas e em meios de comunicação de massa. No entanto, resta saber qual foi a quantidadee aqualidade dessas informações, bem como a integração com a prática profissional. Ainda assim, acredita-se que tais informações poderiam ter sido potencializadas com a discussão de fatores de risco e políticas públicas, praticamente inexistentes nos relatos dos participantes.

Os conteúdos sobre prevenção também foram abordados nas faculdades, mas em número bem reduzido em relação às práticas curativas dos pacientes traumatizados. Sabe-se que é preciso formar um profissional capaz de reabilitar as seqüelas resultantes dos traumas acidentais, no entanto, a predominância dessa visão reduz a probabilidade de reflexão sobre atividades preventivas. A inserção ou ampliação de conteúdos e práticas educativas para a prevenção dos agravos à saúde fortalece a possibilidade de realização de projetos educativos nos diferentes cenários de ensino-aprendizagem. Além disso, essa vivência na faculdadesensibiliza o profissional para atuar de forma preventiva com o tema nos locais em que for trabalhar posteriormente, seja numa instituição educacional ou de saúde.

São várias as possibilidades de atuação na comunidade. Nas instituições educacionais, principalmente nas de ensino infantil e fundamental, seria possível o fonoaudiólogo levantar os riscos deocorrência deacidentes, bem como orientar os funcionários da escola, as crianças e os pais sobre possíveis medidas preventivas que deveriam ser adotadas $^{27}$. N as instituições de saúde, haveria possibilidade de planejar ações preventivas em UBSs, junto aos agentes comunitários e médicos 
pediatras, para as mães quelevam seus filhos para consulta ou vacinação ${ }^{28}$. Nas USFs, o fonoaudiólogo poderia realizar visitas domiciliares, levantar os riscos para acidentes nas residências e, junto à equipe de saúde, orientar as famílias sobre as situações em que estão expostas ${ }^{29}$.

Os incentivos para estas práticas poderiam ser realizados durante a formação universitária pelos docentes, discentes, assim como coordenadores dos cursos. Se todos unissem esforços para a discussão do tema em suas disciplinas ou estágios, certamente formariam profissionais capacitados para a redução dos agravos à saúde e, conseqüentemente, para a melhoria da qualidade de vida da população. Esse problema parece ser de responsabilidade das disciplinas pre ventivas, conforme apontado pelos docentes e discentes, mas requer esforços de todas as áreas para solucioná-lo, pela dificuldade de resolução deste problema e dimensão de sua importância.

Além disso, a inserção de conteúdos sobrecausas externas acidentais nos currículos, bem como a ampliação daquel es existentes nos cursos, poderiam ocorrer de forma articulada com a prática, não somente nas aulas teóricas, como foi indicado pelos participantes desteestudo. Essa forma de ensino e aprendizagem não tem sido indicada como um bom modelo educativo, pois costuma ser centrada no professor e dissociada da prática. É importante a adoção de metodologias que estejam sustentadas na integração curricular, em modelos pedagógicos mais interativos eem estratégias que permitam a participação ativa dos graduandos no diferentes cenários de prática ${ }^{30}$.

\section{Conclusão}

A educação básica é a melhor tentativa para resolver os problemas causados pelas injúrias e podeser realizada pelo fonoaudiólogo, poiséum profissional também voltado à melhoria da qualidade de vida da população.

0 presente estudo mostrou que houve reconhecimento da importância da temática pelos docentes e discentes de cursos superiores de Fonoaudiologia, sendo esta predisposição favorecedora da criação de oportunidades para otimizar atividades de preven ção de acidentes e de introduzir novos projetos de atuação e de investigação nas faculdades.

Embora a amostra deinstituições participantes seja reduzida e não permita generalizações, sinaliza caminhos que poderiam ser trilhados por elas ou outras faculdades que possuem cursos de Fonoaudiologia ou de áreas afins. N ovas iniciativas dos professores, com a participação constante dos alunos, podem contribuir para a educação de profissionais mais conscientes dos principais problemas de saúde pública.

Acredita-se que, desta forma, os futuros profissionais-docentes estarão preparados para trabalhar com a temática dos acidentes nas comunidades em que se inserirem como profissional e com seus alunos na atuação acadêmica.

Esta rede de formação pode igualmente levar um profissional capacitado a integrar equipes ministeriais e propor projetos de relevância nacional, visando à redução das morbidades e mortalidades procedentes das causas externas acidentais.

Para os docentes, discentes edemais profissionais que porventura já realizam algo nesta direção, esta pesquisa reforça a importância da continuidade desta postura, ampliando as ações de ensino, pesquisa e extensão, assim como divulgando as experiências realizadas e os resultados obtidos. 


\section{Colaboradores}

EN N ascimento trabalhou na coleta eanálise dos dados, bem como na redação do artigo; SR Gimeniz-Paschoal orientou a pesquisa e participou da discussão e correção do trabalho.

\section{Agradecimentos}

Agradecemos ao CN Pq pelo financiamento concedido durante os dois anos da pesquisa.

\section{Referências}

1. Brasil. Ministério da Saúde. Secretaria de políticas de saúde. Política nacional de redução da mortalidade por acidentes e violências. Rev. Saúde Pública 2000; 34(4):427-430.

2. Classificação Internacional de Doenças. Décima revisão. [acessado 2005 set 11]. Disponível em: http:// www.datasus.gov.br/cid10/webhelp/cid10.htm

3. Koizumi MS, Mello-Jorge MHP, Nobrega LRB, Waters C. Crianças internadas por traumatismo crânio-encefálico, no Brasil, em 1998: causas e prevenção. Inf Epidemiol SUS 2001; 10(2):93-101.

4. Koizumi MS, Lebrão ML, M ello-Jorge MHP, Primerano V. Morbimortalidade por traumatismo crânio-encefálico no município de São Paulo, 1997. Arq Neuro-Psiquitr. 2000; 58(1):81-89.

5. Dantas Filho VP, Falcão ALE, Sardinha LAC, Facure JJ, Araújo S, Terzi RGG. Aspectos técnicos da monitorização da pressão intracraniana pelo método subaracnóideo no traumatismo cranioencefálico grave. Arq Neuro-Psiquitr. 2001; 59(4):895-900.

6. M elo JR, Silva RA, Moreira Júnior ED. Características dos pacientes com trauma cranioencefálico na cidade de Salvador, Bahia, Brasil. Arq NeuroPsiquitr. 2004; 63(3):711-715.

7. Linden WJVD, Dent M. Dislocated fracture of the mandibular condylar process after airbag deployment: report of a case. J Oral M axillofac Surg. 2004; 62:1341-1346.

8. Cox D, Vincent DG, Mcgwing G, Maclennan PA, Holmes JD, Rue LW. Effect of restraint systems on maxillofacial injury in frontal motor vehicle collisions. J Oral M axillofac Surg. 2004; 62:697-701.

9. Suhr M, Kreusch T. Burn injuries resulting from (accidental) airbag inflation. J Cranio Maxillofac Surg. 2004; 32:35-37.

10. Yaremchuk K, Dobie RA. Otologic injuries from airbag deployment. Otolaryngol Head N eck Surg. 2001; 125:130-134.

11. Gandelmann I, M edeiros PJ, Boghossian LC. Fraturas da face. In: Freire E. Trauma: a doença do século. São Paulo: Atheneu; 2001. p. 1295-1309.

12. Buck I. Trauma craniano: seqüelas neurológicas. J Paran Pediatr. 2003; 4(3):141.

13. Dantas Filho VP, Falcão ALE, Sardinha LAC, Facure JJ, Araújo S, Terzi RGG. Fatores que influenciaram a evolução de 206 pacientes com traumatismo craniencefálico grave. Arq Neuro-Psiquiatr. 2004; 62(2):313-318.

14. Martin RJ, Carey VM, Philbert RF, Carter JB. Prevention of hematomas after auricular injuries. $\mathrm{Br}$ J Oral M axillofac Surg. 2000; 38:238-240.

15. Russo ICP, Santos TMM. Caracterização audiológica das principais patologias do ouvido. In: Russo ICP, Santos TM M. A prática da audiologia clínica. São Paulo: Cortez; 1993. p. 213- 253.

16. Diógenes $S$. Deficiências auditivas adquiridas. In: Pinheiro SD, Freitas MR, Nunes AAA. Otorrinolaringologia para a graduação. Fortaleza: Editora UFC; 2002. p. 193- 205.

17. Mckennan KX, Chole RA. Facial paralysis in temporal bone trauma. Am J Otol. 1992; 13(2):167-172. 
18. Ishman SL, Friedland DR. Temporal bone fractures: traditional classification and clinical relevance. Laryngoscope 2004; 114(10):1734-1741.

19. Antunes ML, Testa JRG. Paralisia facial periférica traumática: achados clínico-cirúrgico de 10 anos. Acta Awho 2000; 19(1):39-41.

20. Lazarini PR, Fernandes AMF, Brasileiro VSB, Custódio SEV. Paralisia facial periférica por comprometimentos do tronco cerebral: a propósito de um caso clínico. Rev Bras Otorr. 2002; 68(1):140-143.

21. Trawitzki LV. Traumas de face: atuação fonoaudiológica em equipe hospitalar. In: Comitê de Motricidade Oral da SBFa. Como atuam os especialistas. São Paulo: Pulso; 2004. p. 99-106.

22. Brito Neto R, Kioshi $H$, Akamini A. Estenose laríngea. Sem Otorr. 1999; 5(2):4-13.

23. Sidle DM, Altman KW. The contralateral injury in blunt laryngeal trauma. Laryngoscope 2002; 112 ( 9):1696-1698.

24. Mello Jorge MHP, Gawryszewski VP, Latorre MRD. O. Análise dos dados de mortalidade. Rev. Saúde Pública 2000; 31(4):5-25.

25. Blank D. Prevenção e controle de injúrias físicas: saímos ou não do século 20? J Pediatr. 2002; 78:84-86.

26. Iunes R F. Impacto econômico das causas externas no Brasil: um esforço de mensuração. Rev. Saúde Pública 1997; 31(4):38-46.

27. Oliveira RA. Educação infantil e acidentes: opiniões dos profissionais e caracterização dos riscos do ambiente educativo [dissertação]. M arília (SP): Universidade Estadual Paulista; 2003.

28. Gimeniz-Paschoal SR. Prevenção de quedas acidentais de bebês: uma intervenção do psicólogo com mães usuárias do setor de pediatria de um centro de saúde de São Paulo [tese]. São Paulo (SP): Universidade de São Paulo; 1998.

29. Morro E, Gimeniz-Paschoal SR, Neves E, Gonsales TP, Oliveira RA. Estratégias educativas para prevenção de acidentes infantis: opiniões de usuários de unidades básicas de saúde (UBSs) e unidades de saúde da família (USFs) do município de MaríliaSP. Revista Olho M ágico 2006; 13(2).

30. Feuerwerker LCM, Sena RR. Contribuição ao movimento de mudança na formação profissional em saúde: uma avaliação das experiências da UNI. Interface - Comunic., Saúde, Educ. 2002; 6(10):37-50.

Aprovado em 02/03/2007

Versão final apresentada em 20/03/2007 